\title{
Economy of heat recovery from mining water in Ostrava region conditions
}

\author{
Petra Petričko ${ }^{1}$, David Kupka ${ }^{1}$, Jan Koloničný ${ }^{1 *}$, and Aleš Richter ${ }^{1}$ \\ ${ }^{1}$ VŠB - Technical University of Ostrava, Energy Research Center, 17. listopadu 15, 70833 Ostrava, \\ Czech Republic
}

\begin{abstract}
The aim of the article is to assess the possibilities of using lowpotential heat by means of industrial heat pumps for heating purposes. The article focused on a relatively specific area, namely the geothermal energy of mine water.
\end{abstract}

\section{Introduction}

The article deals with the use of waste heat in mine water. It solves the technical solution of the actual realization, which is specific in connection with the chemical composition of the mine water, but also deals with the economic and balance solution of the connection of the proposed heat pumps to the central heat supply system. The technical solution was also calculated from the economic indicators in comparison with the installation of the classic gas boiler room.

\section{Mining water issues}

A suitable source of low-potential heat is mine water in flooded areas of deep mines. The water is located deep enough to ensure both the qualitative stability given by the chemical composition and the temperature of the mine water, as well as the quantitative stability expressed by the retention volume of the mine workings, which provides sufficient reserve in the required yield for the economical operation of the current types of heat pumps. The amount of mine water accumulated in the underground at the selected mining sites is shown in the Table 1.

Table 1. The amount of mine water accumulated in the underground at the selected mining sites [1].

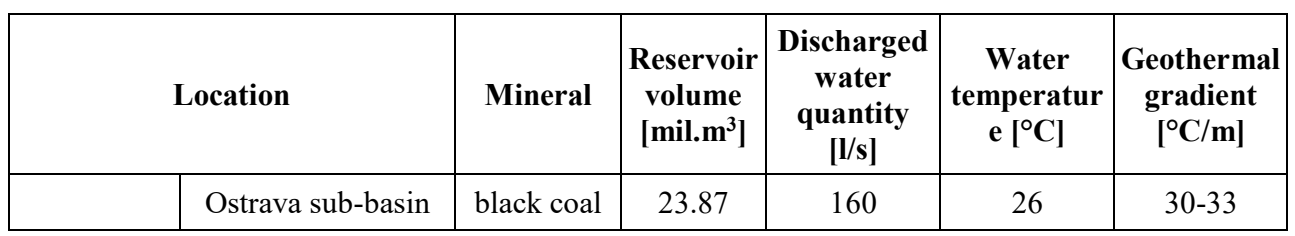

* Corresponding author: jan.kolonicny@,vsb.cz 


\begin{tabular}{|c|c|c|c|c|c|c|}
\hline $\begin{array}{l}\text { Ostrava- } \\
\text { Karvina } \\
\text { coal basin }\end{array}$ & Karvina sub-basin & black coal & 3.63 & 38 & 25 & $30-33$ \\
\hline \multicolumn{2}{|c|}{ Rosicko-oslavanská basin } & black coal & 10 & 55 & 14 & 52 \\
\hline \multicolumn{2}{|l|}{ Zlate Hory } & $\begin{array}{c}\text { non-ferrous } \\
\text { metals }\end{array}$ & 0.14 & 60 & $8-10$ & 67 \\
\hline \multicolumn{2}{|l|}{ Pribram } & uranium & 22 & $80-90$ & 21 & 57 \\
\hline \multicolumn{2}{|l|}{ Olsí } & uranium & 1.84 & 7 & $10-12$ & 55 \\
\hline
\end{tabular}

With regard to the magnitude of the energy potential, the possibilities of utilization of the geothermal energy of mine water in the Ostrava-Karviná basin (OKB) were evaluated. It is divided into three sub-basins - Ostrava (OSB), Petřvald (PSB) and Karviná (KSB) sub-basin. In order to prevent mining waters from flowing from the OSB as well as PPB into functional mines in the Karviná area, and at the same time to eliminate risk of poisoning and explosions due to emissions of coalbed gas on the surface, the level of the mine waters must be maintained at the specified level. In the OPB this is performed by means of central pumping from a single mine - Jeremenko water pit (JWP). Mining water is currently discharged without any benefit to the Ostravice River, which causes the thermal and chemical pollution of the river.

An analysis of the mine environment in the OKB was carried out in terms of the yield of the source, the chemical composition and the temperature of the mine waters. The most promising from the point of view of the use of geothermal energy by heat pumps is the mining water from JWP.

The main qualitative parameters of the mine water are $\mathrm{SO}^{2-}$ and $\mathrm{Cl}^{-}$. These indicators have been identified from the outset as indicative and are therefore regularly monitored. Over time, the Fe content has come into the sphere of interest, especially due to the visual effect in the area of the discharging object. In other hydrochemical parameters, mine water does not appear to be problematic. However, mine water is highly mineralized and therefore very aggressive to conventional materials. The key parameter in terms of energy balance is the water temperature, which is around $25^{\circ} \mathrm{C}$ throughout the year.

\section{Technical solution for the use of mine water}

For the mining of mineral water used as a source of thermal energy, two basic technical solutions and their possible combinations according to the specific conditions of the given site are possible:

- mining water extraction at a location where mining water is controlled from underground,

- $\quad$ create a separate sampling point for these purposes only.

The disadvantage of the first solution is usually the lower temperature of the mine water and usually the location outside the area of energy consumption. These disadvantages can be eliminated by realizing the second solution, but at the cost of building two separate wells (pumping and overflowing). The technological arrangement of the geothermal heating plant for the first variant was proposed, since JWP is located directly in Ostrava near potential consumers. 
Drainage of mining water with the help of a submersible high-pressure aggregate takes place all year round with a flow rate of 160 to $170 \mathrm{l} / \mathrm{s}$. The available energy potential from this heat source through heat pumps is about $10 \mathrm{MW}$.

The proposed technology for the use of geothermal power of mine water consists of a set of 7 water/water heat pumps with partial output of $1.45 \mathrm{MW}$ connected in a cascade. The circulation of the refrigerant is provided by semi-hermetic piston compressors to achieve a high output heating water temperature $\left(65\right.$ to $\left.80^{\circ} \mathrm{C}\right)$. The heating system of the heating water by means of a heat pump is designed as a two-exchanger because of the extraordinary aggressiveness of the mine water. The primary water/water heat exchanger passes the thermal energy of pumped mineral water to the heat transfer medium that conveys it to the heat pump. The water heated in the heat pump at about $65{ }^{\circ} \mathrm{C}$ then passes the heat energy into the secondary heat exchanger to the heating water. The water parameters at the heat pump input are given by the temperature of the mine water reduced by the temperature gradient in the separating exchangers.

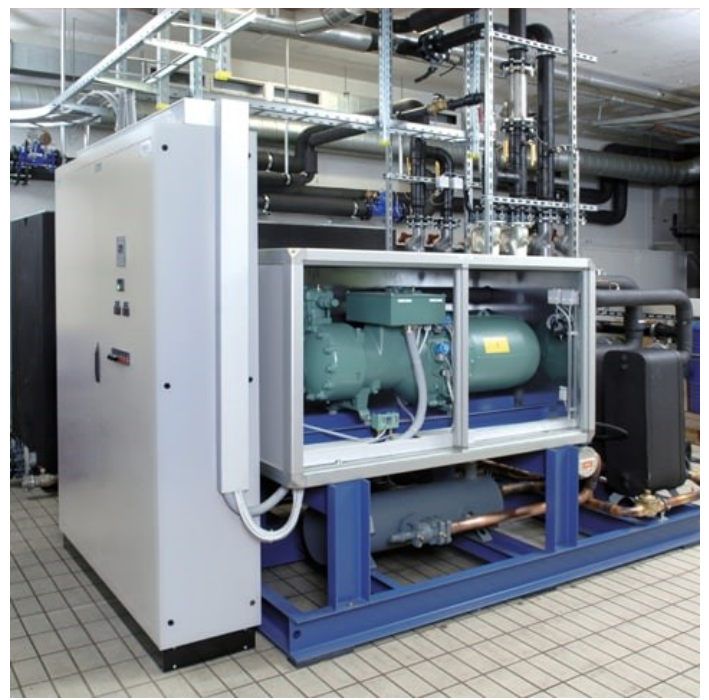

Fig. 1. Industrial heat pump with a capacity of $1.45 \mathrm{MW}$.

\section{Economic evaluation of implementation}

The installed technology was assessed in terms of investment demand and a comparison of the production costs of GJ heat from the geothermal heating plant against the current sources of heat, i.e. mainly the heat produced in the natural gas boiler and the heat extracted from the central supply system. On the basis of the heat pump installed capacity and the expected annual operation, the energy consumption balance and the amount of heat produced were calculated.

Table 2. Basic parameters of installed heat pumps.

\begin{tabular}{|c|c|c|}
\hline Parameter & Unit & Value \\
\hline Number of heat pumps installed & - & 7 \\
\hline Maximum heat output of one heat pump & MW & 1.5 \\
\hline
\end{tabular}




\begin{tabular}{|c|c|c|}
\hline Total installed heat pump heat output & MW & 10.2 \\
\hline $\begin{array}{c}\text { Installed electrical input of one heat } \\
\text { pump }\end{array}$ & MW & 0.5 \\
\hline $\begin{array}{c}\text { Total installed heat input of the heat } \\
\text { pump }\end{array}$ & MW & 3.8 \\
\hline
\end{tabular}

The Figure 2 illustrates the schematic connection and the heat pump principle. The design is considered with R134a refrigerant due to its use for higher output temperatures.

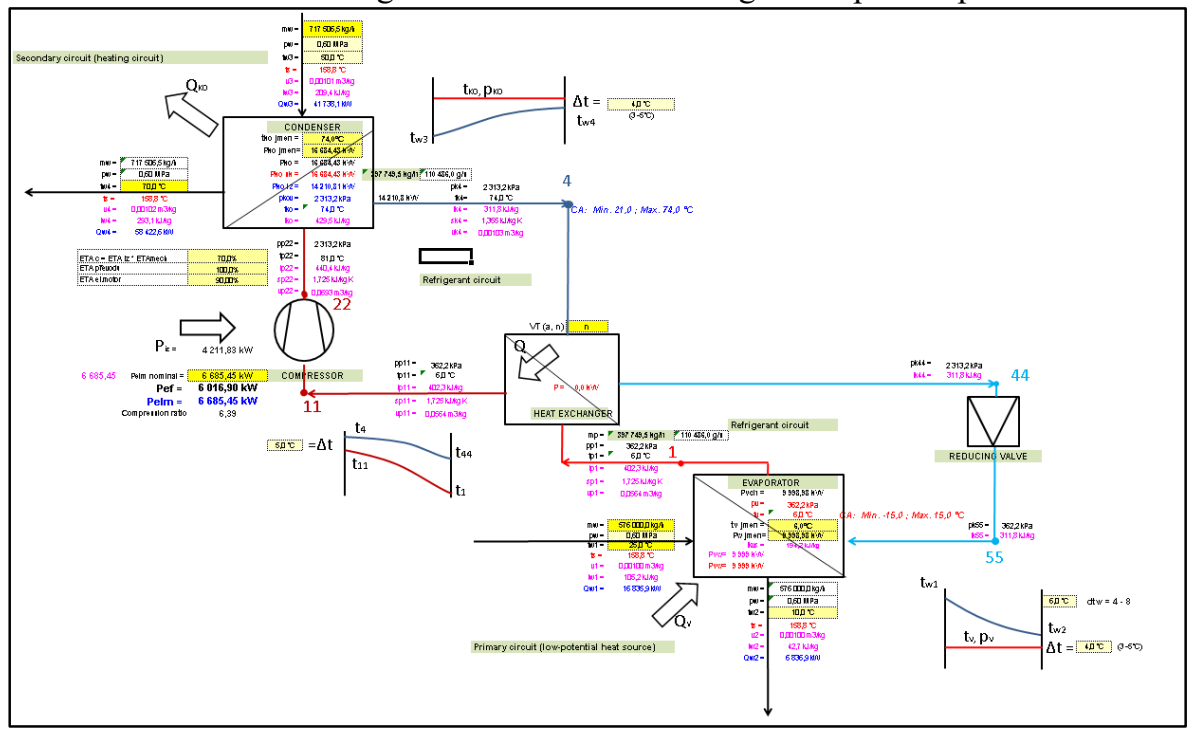

Fig. 2. Basic diagram of the principle of the heat pump connection.

The heat of mine water is fed to an evaporator with mass flow set at the value from 160 to $170 \mathrm{l} / \mathrm{s}$ at temperature $25^{\circ} \mathrm{C}$. According to the input parameters, the thermal output that can be obtained from the mine water is $10 \mathrm{MW}$, if it is considered with the cooling of the mine water at $10{ }^{\circ} \mathrm{C}$. Optimum temperature is required to deliver compression work. The design of the compressor performance is based on the required performance and characteristics of the refrigerant R134a. In order to evaluate the advantage of installing heat pumps, it is necessary to know the balance of the heat produced, including the actual heating factor of the proposed system. Table 3 summarizes the most important installation parameters.

Table 3. Balance of design of heat pumps using mining water with determination of heating factor.

\begin{tabular}{|c|c|c|}
\hline Parameter & Unit & Value \\
\hline Thermal output (heating capacity) & $\mathrm{kW}$ & 9999 \\
\hline Mass flow rate of refrigerant (working fluid) & $\mathrm{kg} / \mathrm{h}$ & 397750 \\
\hline Mass flow of heating water (output) & $\mathrm{kg} / \mathrm{h}$ & 717507 \\
\hline Mass flow rate of mine water (heat source) & $\mathrm{kg} / \mathrm{h}$ & 576000 \\
\hline Evaporation pressure, evaporator temperature & $\mathrm{kPa},{ }^{\circ} \mathrm{C}$ & $362 ; 6$ \\
\hline Condensing pressure, condenser temperature & $\mathrm{kPa},{ }^{\circ} \mathrm{C}$ & $2313 ; 74$ \\
\hline
\end{tabular}




\begin{tabular}{|c|c|c|}
\hline Compression ratio & - & 6.39 \\
\hline Isentropic efficiency & $\%$ & 70 \\
\hline Isentropic compressor power & $\mathrm{kW}$ & 4212 \\
\hline Real compressor power & $\mathrm{kW}$ & 6017 \\
\hline Power consumption of the compressor motor & $\mathrm{kW}$ & 6686 \\
\hline Condenser power output & $\mathrm{kW}$ & 14211 \\
\hline Coefficient of performance - no auxiliary energy & - & 3.37 \\
\hline
\end{tabular}

Investment costs in Table 4 are determined on the basis of indicative offers from technology manufacturers.

Table 4. Estimation of investment costs for the implementation of a new heat source.

\begin{tabular}{|c|c|c|}
\hline Item & Unit & Value \\
\hline $\begin{array}{l}\text { Installed heat sources and other boiler room } \\
\text { technologies }\end{array}$ & \multirow{6}{*}{ thous. CZK } & \multirow{6}{*}{62000} \\
\hline - heat pumps & & \\
\hline - accessories for heat pumps & & \\
\hline - storage tank & & \\
\hline - special exchanger (mineralized mine water) & & \\
\hline - circulating pumps & & \\
\hline Other & \multirow{4}{*}{ thous. $\mathrm{CZK}$} & \multirow{4}{*}{10500} \\
\hline - measurement and control & & \\
\hline - installation and commissioning & & \\
\hline $\begin{array}{c}\text { - other (PDs, related technologies, building } \\
\text { modifications, etc.) }\end{array}$ & & \\
\hline Total cost of investment (excluding VAT) & thous. CZK & 72500 \\
\hline
\end{tabular}

Heat consumption in central heat supply systems is characterized by peak take-offs in the morning and evening hours and, in the summer months, there is a significant decrease due to heat consumption only for the preparation of hot water. For this reason, it is assumed that the installed thermal output is $60 \%$. The price of electricity (fixed cost + reserved capacity) that is included in the calculations is based on average rates for 2017 in the Czech Republic.

Table 5. Determination of energy costs for heat production from the system.

\begin{tabular}{|c|c|c|}
\hline Parameter & Unit & Value \\
\hline Hours of operation & - & 5840.0 \\
\hline Capacity factor & $\%$ & 60.0 \\
\hline Heat production & $\mathrm{GJ} /$ year & 126144 \\
\hline $\begin{array}{c}\text { Electricity consumption by heat pump } \\
\text { compressor }\end{array}$ & $\mathrm{MWh} / \mathrm{year}$ & 10398 \\
\hline Auxiliary power consumption & $\mathrm{MWh} / \mathrm{year}$ & 175 \\
\hline Total electricity consumption for heat production & $\mathrm{MWh} / \mathrm{year}$ & 10573 \\
\hline
\end{tabular}




\begin{tabular}{|c|c|c|}
\hline Average price of electricity - fixed costs & CZK/MWh & 902.0 \\
\hline Fixed cost of electricity consumed & thous. CZK/year & 11720 \\
\hline Electricity payment for heat production & thous. CZK/year & 21257 \\
\hline
\end{tabular}

If we want to evaluate the benefits of installing a new heat source that uses geothermal power of mine water, it is necessary to compare the production with another fuel source. A comparison was made with a typical gas boiler with a heat output of $89 \%$. The price of natural gas (fixed cost + reserved capacity) is also based on average rates in the Czech Republic in 2017.

Table 6. Cost of natural gas for the production of heat from a gas boiler room.

\begin{tabular}{|c|c|c|}
\hline Parameter & Unit & Value \\
\hline Heat production in gas boiler room & GJ/year & 126144 \\
\hline Average efficiency & - & 0.89 \\
\hline $\begin{array}{c}\text { Consumption of natural gas for the production of } \\
\text { heat }\end{array}$ & GJ/year & 141735 \\
\hline Average natural gas price - fixed costs & CZK/MWh & 167 \\
\hline Fixed cost of collected electricity & thous. CZK/year & 1925 \\
\hline New payment for natural gas for heat production & thous. CZK/year & 25589 \\
\hline
\end{tabular}

Table 7. Cost savings in heat production from geothermal heating plant.

\begin{tabular}{|c|c|c|}
\hline Parameter & Unit & Value \\
\hline Cost of heat produced in a gas boiler & thous. CZK/year & 25589 \\
\hline Costs of heat produced in heat pumps & thous. CZK/year & 21257 \\
\hline Cost saving on heat generation from geothermal energy & thous. CZK/year & 4332 \\
\hline
\end{tabular}

Note: Only energy costs are evaluated, the evaluation does not include overheads, wages, insurance, etc. It is assumed that the geothermal heating plant is identical to the cost of operating the gas boiler.

Table 8. Economic evaluation of the new geothermal heating plant.

\begin{tabular}{|c|c|c|}
\hline Parameter & Unit & Value \\
\hline Investment costs & thous. CZK & 72500 \\
\hline Operating revenue & thous. CZK/year & 25589 \\
\hline Operating costs & thous. CZK/year & 2125 \\
\hline Cash flow (CF) & thous. CZK/year & 4332 \\
\hline Discount Rate & $\%$ & 4.00 \\
\hline Net Present Value NPV & thous. CZK & -11272 \\
\hline Internal Revenue Rate IRR & $\%$ & 2.0 \\
\hline Payback period & years & 16.7 \\
\hline Real time of return & years & $>\mathrm{EP}$ \\
\hline Evaluation period (EP) & years & 20 \\
\hline Accumulated CF at the end of the EP & thous. CZK & 14140 \\
\hline
\end{tabular}




\section{Conclusion}

Within the activity, research and development work was carried out, aiming at a theoretical assessment of the possibility of using heat pumps for the use of geothermal energy contained in mine waters. Due to the significant energy potential, the proximity of consumers and the favorable parameters of the mine waters, the area of the Ostrava sub-basin (OSB), which is part of the Ostrava-Karviná district, was analyzed in detail. From the OSB, the mining water is currently discharged to the surface through a central pit and is discharged into the Ostravice River. A technical solution in the form of a $10 \mathrm{MW}$ geothermal power plant based on industrial heat pump technology was proposed to use the low-potential heat of these waters. Both the technical requirements resulting from the problematic composition of the mine water and the economy of the operation of this source were taken into account compared to the traditional technologies.

Mining water is highly aggressive due to high mineralization, which means it cannot be fed directly to the heat exchanger that forms the evaporator of the heat pump. For this reason, the low-potential heat from the mine water must be indirectly discharged with the aid of an inlet circuit in which the intermediate heat transfer medium flows. This fact exacerbates the realization of the geothermal heating plant. A technical - economic evaluation of this implementation has been carried out. The operation economy of the new source was compared with the operation of the classic gas boiler room with an efficiency of $89 \%$. According to economic appreciation, the payback time of the new heating plant is 16.7 years. When considering a $4 \%$ discounted rate and a 20 -year evaluation period, the return on investment is beyond the lifetime.

The optimization of the technical solution for the realization of a geothermal heating plant of this magnitude depends mainly on the development in the field of heat pumps. More detailed design and evaluation is a matter of next year's research.

This article was published with the support Student Grant Competition project entitled Technology for Waste Energy Utilization, no. SP2017/179, and project „Innovation for Efficiency and Environment - Growth", identification code LO1403 with the financial support from the Ministry of Education, Youth and Sports in the framework of the National Sustainability Programme I.

\section{References}

1. B. Michálek, D. Holéczy, P. Jelínek, A. Grmela, Acta Montanistica Slovaca, 12, 92 (2007) 